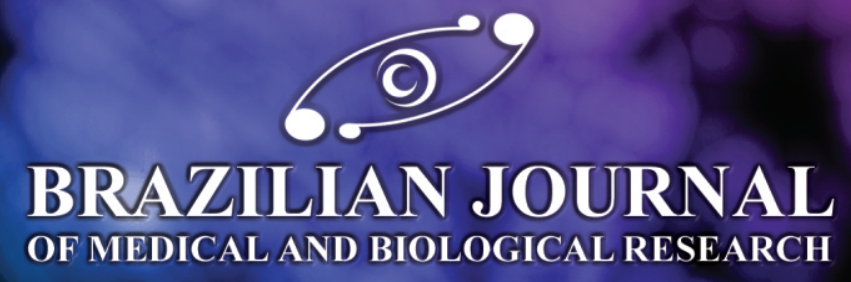
www.bjournal.com.br
ISSN 1414-431X

Volume 45 (12) 1102-1340 December 2012

\section{BIOMEDICAL SCIENCES}

AND

CLINICAL INVESTIGATION

Braz J Med Biol Res, December 2012, Volume 45(12) 1157-1162

doi: 10.1590/S0100-879X2012007500149

In vitro cultivation of canine multipotent mesenchymal stromal cells on collagen membranes treated with hyaluronic acid for cell therapy and tissue regeneration

T.I. Wodewotzky, J.F. Lima-Neto, O.C.M. Pereira-Júnior, M.J. Sudano, S.A.F. Lima, P.R.O. Bersano, S.A. Yoshioka and F.C. Landim-Alvarenga

The Brazilian Journal of Medical and Biological Research is partially financed by

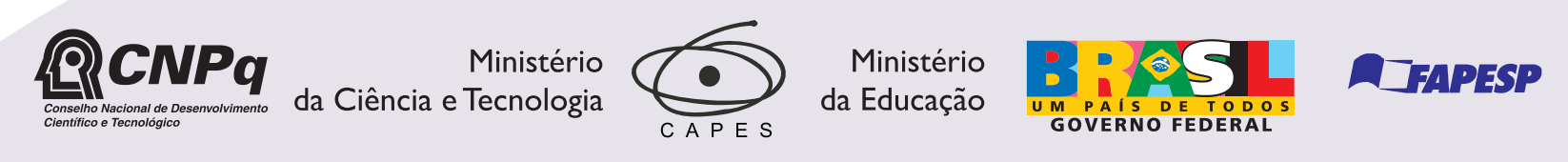
Institutional Sponsors

Sciezo
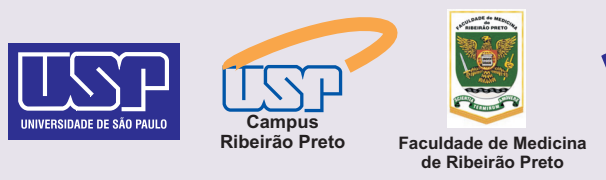

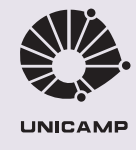

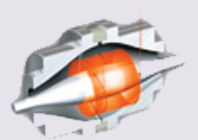

Ф SHIMADZU

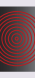

1 Associaçäa
Fundo
delncentivo de Incentivo
à Pesquisa

plore High - Performance MS Orbitrap Technology analitica Thermo 


\title{
In vitro cultivation of canine multipotent mesenchymal stromal cells on collagen membranes treated with hyaluronic acid for cell therapy and tissue regeneration
}

\author{
T.I. Wodewotzky1, J.F. Lima-Neto1, O.C.M. Pereira-Júnior ${ }^{1,2}$, M.J. Sudano1, S.A.F. Lima1, \\ P.R.O. Bersano ${ }^{3}$, S.A. Yoshioka ${ }^{4}$ and F.C. Landim-Alvarenga ${ }^{1}$ \\ ${ }^{1}$ Departamento de Reprodução Animal e Radiologia Veterinária, Faculdade de Medicina Veterinária e Zootecnia, \\ Universidade Estadual de São Paulo, Botucatu, SP, Brasil \\ ${ }^{2}$ Departamento de Cirurgia e Anestesiologia Veterinária, Faculdade de Medicina Veterinária e Zootecnia, \\ Universidade Estadual de São Paulo, Botucatu, SP, Brasil \\ ${ }^{3}$ Departamento de Patologia Veterinária, Faculdade de Medicina Veterinária e Zootecnia, \\ Universidade Estadual de São Paulo, Botucatu, SP, Brasil \\ ${ }^{4}$ Instituto de Química de São Carlos, Universidade de São Paulo, São Carlos, SP, Brasil
}

\begin{abstract}
Support structures for dermal regeneration are composed of biodegradable and bioresorbable polymers, animal skin or tendons, or are bacteria products. The use of such materials is controversial due to their low efficiency. An important area within tissue engineering is the application of multipotent mesenchymal stromal cells (MSCs) to reparative surgery. The combined use of biodegradable membranes with stem cell therapy may lead to promising results for patients undergoing unsuccessful conventional treatments. Thus, the aim of this study was to test the efficacy of using membranes composed of anionic collagen with or without the addition of hyaluronic acid ( $\mathrm{HA})$ as a substrate for adhesion and in vitro differentiation of bone marrow-derived canine MSCs. The benefit of basic fibroblast growth factor (bFGF) on the differentiation of cells in culture was also tested. MSCs were collected from dog bone marrow, isolated and grown on collagen scaffolds with or without HA. Cell viability, proliferation rate, and cellular toxicity were analyzed after 7 days. The cultured cells showed uniform growth and morphological characteristics of undifferentiated MSCs, which demonstrated that MSCs successfully adapted to the culture conditions established by collagen scaffolds with or without HA. This demonstrates that such scaffolds are promising for applications to tissue regeneration. bFGF significantly increased the proliferative rate of MSCs by $63 \%$ when compared to groups without the addition of the growth factor. However, the addition of bFGF becomes limiting, since it has an inhibitory effect at high concentrations in culture medium.
\end{abstract}

Key words: Collagen scaffolds; Biomaterials; Hyaluronic acid; Mesenchymal stromal cells; Tissue engineering; Cell culture

\section{Introduction}

Among adult animal stem cells, those from bone marrow have received great attention due to their easy isolation and culture, high in vitro expansion potential (1-3), and ability to differentiate into mesenchymal (4), ectodermal $(5,6)$, and endodermal (7) cells. These cells have the capacity to differentiate into bone, cartilage, fat tissue, tendon, muscle $(8,9)$, mature hepatocytes, epithelial cells of the skin and intestinal tract, and may improve heart function after myocardial infarction (10-12).

Numerous tissue engineering strategies are available today for the regeneration of wounded skin. The use of collagen membrane gels as biomaterials in plastic surgery is one of them and has greatly improved in recent decades. This has ultimately led to an increased interest in developing biodegradable and biocompatible materials for tissue regeneration (13-15). The increasing importance of collagen in the area of biomaterials is due to its great abundance in the animal kingdom, the ease in obtaining it, and its positive physical and physicochemical properties for specific applications in biomaterials.

Hyaluronic acid (HA) has a high ability to absorb water, which influences several cellular functions such as migration, adhesion, and cell proliferation $(16,17)$. Furthermore,

Correspondence: T.I. Wodewotzky, Departamento de Reprodução Animal e Radiologia Veterinária, Faculdade de Medicina Veterinária e Zootecnia, UNESP, 18618-000 Botucatu, SP, Brasil. E-mail: thabetzky@hotmail.com

Received April 21, 2012. Accepted September 10, 2012. Available online September 21, 2012. Published December $17,2012$. 
HAis a major component of the extracellular matrix of mammals. Therefore, its application to the field of biomaterials is promising, currently being used as bio-implants for the treatment of voice disorders (18), and as an injectable gel in plastic surgery for the management of facial aging $(16,19)$.

Among growth factors, the fibroblast growth factor (FGF) family (22 family members) is of great importance in the process of tissue regeneration. Most members of this family have a wide range of mitogenic action and can stimulate the proliferation of cells of ectodermal, mesodermal, and endodermal origin (20).

Treatment based on biomaterials is still controversial due to its low efficiency. However, it is believed that the combined use of biodegradable membranes with stem cell therapy may generate promising results for patients submitted to unsuccessful conventional treatments (21). Thus, compounds made from the combination of collagen, $\mathrm{HA}$, and growth factors for the application of injectable biomaterials or in the form of membranes have been developed to attract cells, serving as a scaffold for tissue growth (14).

In this study, bone marrow-derived canine mesenchymal stromal cells (MSCs) were applied to an anionic collagen membrane with and without HA(22). The membrane served as support for adhesion and growth of the cells to develop a cellularized graft and to assess the effect of basic FGF (bFGF) on the proliferation of cultured MSCs.

\section{Material and Methods}

\section{Preparation of biocomposites from native and anionic collagen}

Anionic collagen (Coll) was developed by the Department of Biomaterials, USP, São Carlos, SP, Brazil (22).

$\mathrm{HA}$, obtained for the manufacture of membranes, was extracted from chicken ridges using a method developed by the team of Biochemistry and Biomaterials from the São Carlos Institute of Chemistry (USP), which is a proprietary process (patent pending).

For the preparation of the composites, 10:1 and 100:1 ratios (Coll:HA) were used. After mixing, the $\mathrm{pH}$ of the gel formed was adjusted with acetic acid until the solution reached $\mathrm{pH} 3.5$, followed by a gel degassing procedure. This procedure removes oxygen bubbles from the gel to facilitate molding.

The collagen membranes (CollM) were prepared on 24well microplates (Corning, USA) by coating the wells with $300 \mu \mathrm{L}$ solubilized collagen at $0.1 \%$ concentration (w/w) and left to dry at room temperature under a laminar flow hood for 3 days. After drying, the films were stored in a desiccator until use. The membranes were sterilized by immersion in $70 \%$ ethanol, washed three times with deionized water and exposed to ultraviolet light overnight.

\section{Isolation and in vitro culture of multipotent MSC \\ MSCs were obtained by puncture of the bone marrow of}

dogs from the Veterinary Hospital (HV), School of Veterinary Medicine (FMVZ), UNESP, Botucatu, SP, Brazil. The animals were sedated with acepromazine (2\% Acepran Univet, $\mathrm{SP}$ ) at a dose of $0.05 \mathrm{mg} / \mathrm{kg}$ intramuscularly. After $15 \mathrm{~min}$, general anesthesia was induced with propofol (Diprivan, Zeneca Farmacêutica do Brasil Ltda., Brazil) at a dose of $6 \mathrm{mg} / \mathrm{kg}$, intravenously. The left cephalic vein was cannulated to receive the $0.9 \%$ sodium chloride physiological solution at a dose of $20 \mathrm{~mL} \cdot \mathrm{kg}^{-1} \cdot \mathrm{h}^{-1}$. With the dog positioned in left lateral decubitus, trichotomy and disinfection were performed with chlorhexidine in the right scapular-humeral joint region. Next, a needle for biopsy of the bone marrow was introduced into the great tuberosity of the humerus to reach the spinal canal. The needle was attached to a $20-\mathrm{mL}$ disposable syringe containing $1 \mathrm{~mL}$ sodium heparin (Cristália, Brazil) where, by means of a negative pressure gradient, $5 \mathrm{~mL}$ bone marrow was collected. Blood samples were processed at the Laboratory of Cell Therapy and Advanced Reproduction, Faculty of Veterinary Medicine, UNESP, Botucatu, SP, Brazil, and mononuclear cells were separated by density gradient difference using Ficoll-Paque (density 1077 g/mL, Amersham Biosciences, UK).

Cells were plated in $25-\mathrm{cm}^{2}$ bottles in a high-glucose DMEM medium with 4 mM L-glutamine (Gibco, USA), 20\% fetal bovine serum (Gibco), $100 \mathrm{IU} / \mathrm{mL}$ penicillin and 10 $\mathrm{mg} / \mathrm{mL}$ streptomycin (Sigma-Aldrich, USA), and $3.0 \mu \mathrm{g} / \mathrm{mL}$ amphotericin B (Sigma-Aldrich) for 14 days. The culture medium was replaced every 3 days.

Once the culture reached approximately $80 \%$ confluence, the cells were counted with the aid of a Neubauer chamber (Neubauer Improved, New Optik, Brazil), and transferred at a concentration of $1 \times 10^{5}$ cells $/ \mathrm{mL}$ to microplates containing collagen membranes with and without $\mathrm{HA}$ (CollMHA, Coll:HA, 25:1) at 0.1\% (w/w) and allowed to grow for 7 days.

For the control study, cells were transferred directly to a 24-well microplate without collagen films, which was maintained under the same culture conditions as the other groups.

The study was divided into three parts: 1) comparison between CollM and CollMHA; 2) comparison between MSC culture on CollMHA with or without bFGF (10 and $50 \mathrm{ng} /$ $\mathrm{mL}$; Sigma), and 3) determination of the effect of the addition of bFGF (10 and $50 \mathrm{ng} / \mathrm{mL}$ ) on the proliferation rate of MSCs cultured on CollM. Data were obtained from two independent experiments performed in triplicate with each culture condition.

\section{Quantitative and immunohistochemical analyses of MSCs}

Cell viability was measured by staining cells with Hoechst 33342 (Invitrogen, USA), which stains live cells in blue, and propidium iodide (Sigma-Aldrich), which stains dead or dying cells in red, indicating which cells are undergoing necrosis. For this, the culture medium of the 24 -well plate 
was removed, and $0.5 \mathrm{~mL}$ PBS containing $30 \mu \mathrm{L}$ Hoechst 33342 solution $(10 \mathrm{mg} / \mathrm{mL})$ was added to each well, and maintained for $40 \mathrm{~min}$ at $37^{\circ} \mathrm{C}$. This incubation was followed by the addition of $10 \mu \mathrm{L}$ propidium iodide solution $(1.0 \mathrm{mg} /$ $\mathrm{mL}$ ) and after 5 min cells were analyzed by fluorescence microscopy (excitation: 450 to $490 \mathrm{~nm}$ at $100 \mathrm{X}$ magnification). The methodology was based on the analysis of photomicrographs of cell fields.

To measure the percentage of viable and nonviable cells, cells were classified according to the color of stained cells (blue: live; red: dead), in an area of $50 \mu \mathrm{m}^{2}$. Data were analyzed statistically by the unpaired $t$-test with Welch's correction, with the level of significance set at $P<0.05$. Statistical analyses were performed using the GraphPad InStat 3 statistical package (Graph Pad Software Inc., USA).

MSC viability was also assessed by Trypan blue dye exclusion and quantified by cell-counting in a Neubauer chamber. To detach cells from the membrane surface, 200 $\mu \mathrm{L} 0.25 \%$ Trypsin (LGC, BR30045-01) was added to each well and incubated at $37^{\circ} \mathrm{C}$ for $5 \mathrm{~min}$. For the counts in the Neubauer chamber, 0.4\% Trypan blue (Gibco, 15250-061; $1: 1, v / v)$ was added. This test was conducted in triplicate.

The identities of the MSCs were confirmed by using
$\mathrm{CD}^{+} 4^{+}$and $\mathrm{CD}^{-} 4^{-}$antibodies (BD-Pharmingen, USA), which identify surface markers specific for MSCs. The standard protocol suggested by the manufacturer of each antibody was followed, and samples were analyzed by flow cytometry.

\section{Results and Discussion}

\section{Cell viability analysis}

Cell viability was analyzed from photomicrographs of cell fields following the methods previously described. The cell culture after 7 days of incubation showed more confluency in the culture with the addition of bFGF (Figure $1 A$ and $B$ ). Figure $1 C$ and $D$ show the viable cell nuclei stained in blue (Hoechst 33342) and the nonviable cell nuclei stained in red (propidium iodide). It is possible to visually note that the quantity of dead cells is small (Figure $1 C$ and D).

Statistically, there was no significant difference in cell viability in the control group $(91.8 \pm 3.39 \%)$, on CollM (85.3 $\pm 9.26 \%)$ or CollMHA (85.6 $\pm 4.02 \%$; P > 0.05). The high cell viability rates indicate that the material produced with or without the addition of HA to its composition does not exhibit in vitro cytotoxicity.
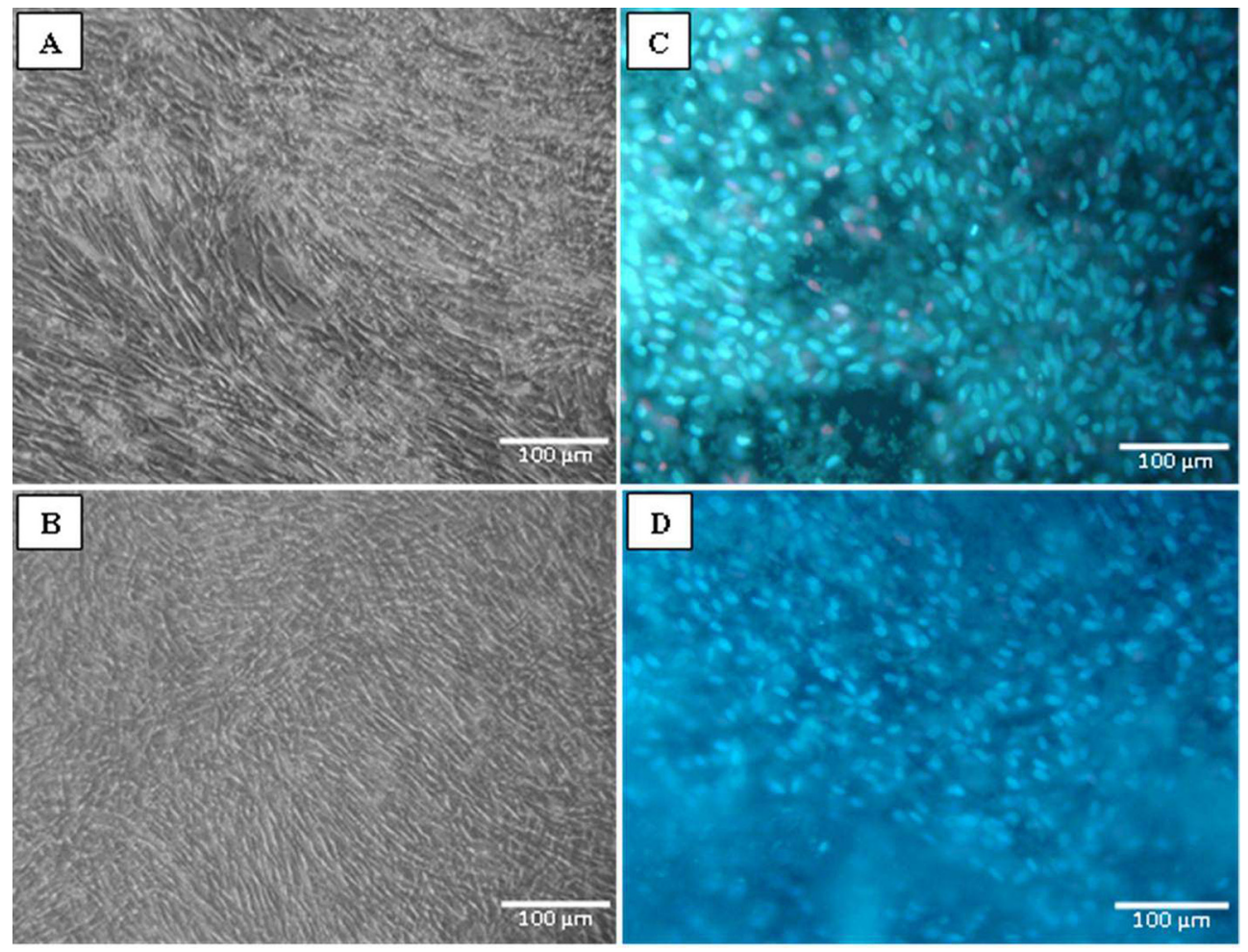

Figure 1. Photomicrographs showing MSCs in culture on CollM ( $A$ and $C$ ) and CollMHA with $10 \mathrm{ng} / \mathrm{mL}$ bFGF $(B$ and $D)$. $A$ and $B$, Observation performed after 7 days of culture showing adherent MSCs after expansion. $C$ and $D$, Live cells (blue) stained with Hoechst 33342 and cells undergoing necrosis (red) stained with propidium iodide. $\mathrm{MSCs}=$ multipotent mesenchymal stromal cells; CollM = collagen membrane; CollMHA = collagen membrane plus hyaluronic acid; bFGF = basic fibroblast growth factor. 
Despite the good biocompatibility shown by both membrane components, the addition of high HA concentrations can cause a relative disadvantage of in vitro culture since it reduces cell adhesion due to the negative charge of the $\mathrm{HA}$ (23). However, this potential disadvantage can be eliminated by modifying the surface with adhesion promoting agents such as laminin and poly-lysine (24). This strategy, however, was not needed in the present study, since the cells showed good adhesion regardless of treatment with $\mathrm{HA}$.

Cell viability was not affected by the addition of bFGF. The percentage of live cells was more than $87 \%$ in all cultures regardless of the bFGF concentration used (data not shown).

Cell viability was not affected by the addition of bFGF, obtaining a percentage of viable cells of $95.96 \pm 4.52$ and $95.75 \pm 3.68$ in the cultures with 10 and $50 \mathrm{ng} / \mathrm{mL}$, respectively (data not shown).

\section{Cell proliferation analysis}

Figure 2A shows the total number of viable cells present in CollM and CollMHA cultures compared to control. The presence of $\mathrm{HA}$ in the collagen matrix caused increased cell growth, adhesion, and proliferation, resulting in better culture conditions and stability. Comparison of the three growth conditions (control, CollM and CollMHA) showed a significant difference $(P<0.05)$; however, there was no significant difference between the control culture and the culture in CollMHA.

In vivo, collagen and $\mathrm{HA}$ are the predominant components of the extracellular matrix during the early stages of tissue repair and, together with fibronectin, laminin, thrombospondin, hemonectin, and proteoglycans, they stimulate migration and cell proliferation, facilitate cell adhesion at the site of new tissue formation, and stimulate differentiation into mature cell types (25). In vitro, the combination of collagen and HA provides a microenvironment chemically similar in part to the in vivo environment $(17,25)$.
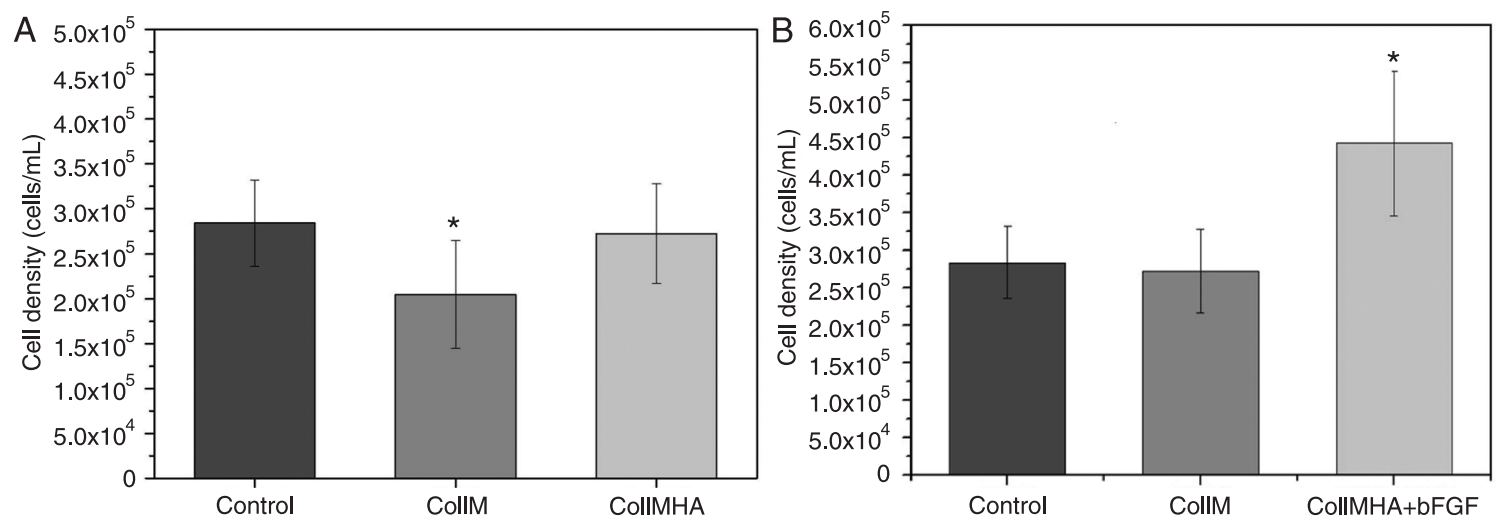

Figure 2. Comparison of the proliferation rates of cultures $(A)$ on collagen membranes (CollM) with and without hyaluronic acid (HA), and $(B)$ on CollM plus HA (CollMHA) with and without basic fibroblast growth factor (bFGF) $(10 \mathrm{ng} / \mathrm{mL}) \mathrm{com}-$ pared to control culture ( ${ }^{*} \mathrm{P}<0.05$, unpaired $t$-test).

\section{Effect of the addition of bFGF on the proliferation rate}

The addition of $10 \mathrm{ng} / \mathrm{mL}$ bFGF to cultures of canine MSCs on CollMHA had a positive effect by significantly increasing the cell proliferation rate. An increase of up to $63 \%$ in the proliferation rate was observed in bFGF-treated cultures compared to cultures containing no additional growth factor (Figure 2B).

The increased cell growth has two potential explanations. It was initially believed that bFGF protects the ends of cell chromosomes (telomeres) from the natural shortening that occurs at each cell division. This would provide the cells with an unlimited proliferative potential, as seen in germ cells, embryonic stem cells, or cancer cells. However, there is no synthesis of telomerase, an enzyme responsible for telomere replacement, in MSCs (26). When measuring the telomere length of MSCs in culture, Bianchi et al. (26) found that bFGF supplementation of bone marrow MSC cultures may promote a selective action of cells, selecting a subset of cells more suitable for mitotic division.

The second specificity of bFGF was attributed by Choi et al. (27), who reported that bFGF binds to membrane tyrosine-kinase catalytic receptors, promoting the cascaded signaling of the ERK1/2 pathway and may also recruit complexes that will activate the PI3K-Akt pathway, which is responsible for promoting increased cell survival.

Figure 3 shows the data regarding the counting of total viable cells, with a comparison between the different bFGF concentrations ( 10 and $50 \mathrm{ng} / \mathrm{mL}$ ) added to the culture media. The cell proliferation rate achieved by adding $10 \mathrm{ng} / \mathrm{mL}$ bFGF was significantly higher than that found for cultures with $50 \mathrm{ng} / \mathrm{mL}$ bFGF and control cultures with no bFGF ( $P$ $<0.05)$. The increase in cell proliferation in cultures with 10 $\mathrm{ng} / \mathrm{mL}$ bFGF was 26.4 and $55.7 \%$ greater compared to the control and $50 \mathrm{ng} / \mathrm{mL}$ bFGF cultures, respectively.

Although $50 \mathrm{ng} / \mathrm{mL}$ bFGF has also led to a significant increase in cell proliferation, the higher concentration resulted in a decline in cell number compared to the samples with a lower concentration of bFGF (28). 


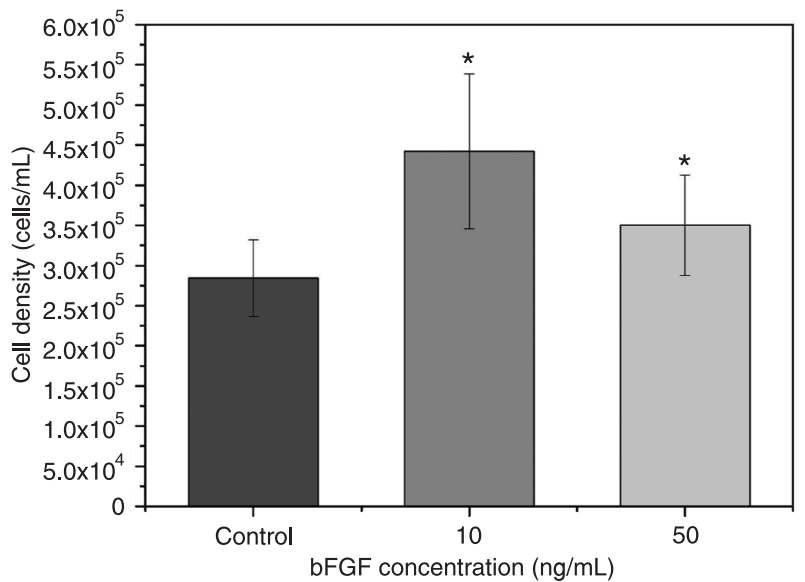

Figure 3. Effect of the concentration of basic fibroblast growth factor (bFGF) on cell proliferation rate. ${ }^{*} \mathrm{P}<0.05$ compared to control culture (unpaired $t$-test).

Proliferative differences could be observed between MSCs cultured with low and high bFGF concentrations, since at high concentrations, bFGF tends to stimulate cell differentiation. Thus, MSCs lose their multipotent characteristic and hence their potential for self-renewal, reducing the population growth $(26,28)$; however, cell differentiation analyses were not conducted in this study.

\section{Flow cytometry analyses of MSCs}

Cell cultures on biomembranes were evaluated with regard to their surface antigens by staining with specific monoclonal antibodies. Flow cytometry analysis indicated that the population of cells derived from the primary culture showed negative reactivity for the CD34 marker, a typical marker for the recognition of stem cells of hematopoietic origin. The cells derived from the primary culture were also positive for CD44 (97\%), a surface antigen involved in cell-

\section{References}

1. Le Blanc K, Tammik C, Rosendahl K, Zetterberg E, Ringden O. HLA expression and immunologic properties of differentiated and undifferentiated mesenchymal stem cells. Exp Hematol 2003; 31: 890-896.

2. Mayhall EA, Paffett-Lugassy N, Zon LI. The clinical potential of stem cells. Curr Opin Cell Biol 2004; 16: 713-720.

3. Pittenger MF, Mackay AM, Beck SC, Jaiswal RK, Douglas $\mathrm{R}$, Mosca JD, et al. Multilineage potential of adult human mesenchymal stem cells. Science 1999; 284: 143-147.

4. Bosnakovski D, Mizuno M, Kim G, Takagi S, Okumura M, Fujinaga T. Isolation and multilineage differentiation of bovine bone marrow mesenchymal stem cells. Cell Tissue Res 2005; 319: 243-253.

5. Wang G, Bunnell BA, Painter RG, Quiniones BC, Tom S, Lanson NA Jr, et al. Adult stem cells from bone marrow
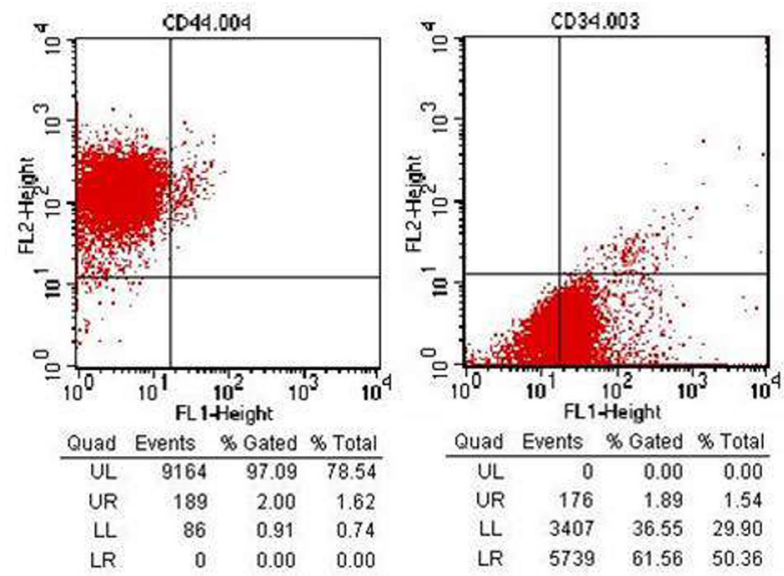

Figure 4. Flow cytometric analysis showing the percentages of cells stained with CD34 and CD44 antibodies. The mesenchymal stromal cells after 7 days of culture were positive for expression of CD44 and negative for CD34.

cell and cell-substrate interactions. CD44 is only expressed in anchorage-dependent cells, indicating that these cells belong to the bone marrow-derived mesenchymal cell lineage, as illustrated in Figure 4.

On the basis of these experiments, we conclude that collagen-based membranes showed a high degree of tissue compatibility and can be considered to be an excellent substrate for adhesion and proliferation of canine MSCs. These properties can be used in clinical practice for the regeneration of damaged tissues. Proliferation was more intense in the presence of the growth factor bFGF, confirming the efficacy of this factor for stimulating cell growth.

\section{Acknowledgments}

Research supported by FAPESP. stroma differentiate into airway epithelial cells: potential therapy for cystic fibrosis. Proc Natl Acad Sci U S A 2005; 102: 186-191.

6. Deng W, Han Q, Liao L, Li C, Ge W, Zhao Z, et al. Engrafted bone marrow-derived flk-(1+) mesenchymal stem cells regenerate skin tissue. Tissue Eng 2005; 11: 110-119.

7. Quevedo HC, Hatzistergos KE, Oskouei BN, Feigenbaum GS, Rodriguez JE, Valdes D, et al. Allogeneic mesenchymal stem cells restore cardiac function in chronic ischemic cardiomyopathy via trilineage differentiating capacity. Proc Natl Acad Sci U S A 2009; 106: 14022-14027.

8. Orlic D, Kajstura J, Chimenti S, Jakoniuk I, Anderson SM, $\mathrm{Li} B$, et al. Bone marrow cells regenerate infarcted myocardium. Nature 2001; 410: 701-705.

9. Fathke C, Wilson L, Hutter J, Kapoor V, Smith A, Hocking 
A, et al. Contribution of bone marrow-derived cells to skin: collagen deposition and wound repair. Stem Cells 2004; 22: 812-822.

10. Satoh H, Kishi K, Tanaka T, Kubota Y, Nakajima T, Akasaka $Y$, et al. Transplanted mesenchymal stem cells are effective for skin regeneration in acute cutaneous wounds. Cell Transplant 2004; 13: 405-412.

11. Korbling M, Katz RL, Khanna A, Ruifrok AC, Rondon G, Albitar M, et al. Hepatocytes and epithelial cells of donor origin in recipients of peripheral-blood stem cells. $N$ Engl $J$ Med 2002; 346: 738-746.

12. Mangi AA, Noiseux $\mathrm{N}$, Kong $\mathrm{D}, \mathrm{He} H$, Rezvani M, Ingwall JS, et al. Mesenchymal stem cells modified with Akt prevent remodeling and restore performance of infarcted hearts. Nat Med 2003; 9: 1195-1201.

13. Angele $P$, Abke J, Kujat $R$, Faltermeier $H$, Schumann $D$, Nerlich $\mathrm{M}$, et al. Influence of different collagen species on physico-chemical properties of crosslinked collagen matrices. Biomaterials 2004; 25: 2831-2841.

14. Fonseca AA. Desenvolvimento de compósitos de colágeno aniônico: ácido hialurônico para obtenção de géis injetáveis. [Master's thesis]: Disciplina SQM5790-9 Seminários em Química (Analítica), Instituto de Química de São Carlos, USP; 2006.

15. Sun B, Ma W, Su F, Wang Y. The osteogenic differentiation of dog bone marrow mesenchymal stem cells in a thermosensitive injectable chitosan/collagen/b-glycerophosphate hydrogel: in vitro and in vivo. J Mater Sci: Mater Med 2011; 22: 2111-2118.

16. Brandt FS, Cazzaniga A. Hyaluronic acid gel fillers in the management of facial aging. Clin Interv Aging 2008; 3: 153159.

17. Jha $\mathrm{AK}, \mathrm{Xu} \mathrm{X}$, Duncan RL, Jia X. Controlling the adhesion and differentiation of mesenchymal stem cells using hyaluronic acid-based, doubly crosslinked networks. Biomaterials 2011; 32: 2466-2578.

18. Chan RW, Titze IR. Dependence of phonation threshold pressure on vocal tract acoustics and vocal fold tissue me- chanics. J Acoust Soc Am 2006; 119: 2351-2362.

19. Narins RS, Brandt FS, Dayan SH, Hornfeldt CS. Persistence of nasolabial fold correction with a hyaluronic acid dermal filler with retreatment: results of an 18-month extension study. Dermatol Surg 2011; 37: 644-650.

20. Kibe Y, Takenaka H, Kishimoto S. Spatial and temporal expression of basic fibroblast growth factor protein during wound healing of rat skin. Br J Dermatol 2000; 143: 720727.

21. Falanga $V$, Sabolinski M. A bilayered living skin construct (APLIGRAF) accelerates complete closure of hard-to-heal venous ulcers. Wound Repair Regen 1999; 7: 201-207.

22. Goissis G, Plepis AMG, Rocha JL. Processo de extração de colágeno de tecidos animais com auxílio de solventes orgânicos e meio alcalino. Patent No. BR PI 9.405.043-0; 1994.

23. Higuchi A, Ling QD, Hsu ST, Umezawa A. Biomimetic cell culture proteins as extracellular matrices for stem cell differentiation. Chem Rev 2012; 112: 4507-4540.

24. Ren YJ, Zhou ZY, Liu BF, Xu QY, Cui FZ. Preparation and characterization of fibroin/hyaluronic acid composite scaffold. Int J Biol Macromol 2009; 44: 372-378.

25. Anjos AR, Borelli P. Matriz extracelular e leucemia. Rev Bras Hematol Hemoter 2000; 22: 404-412.

26. Bianchi G, Banfi A, Mastrogiacomo M, Notaro R, Luzzatto $\mathrm{L}$, Cancedda R, et al. Ex vivo enrichment of mesenchymal cell progenitors by fibroblast growth factor 2. Exp Cell Res 2003; 287: 98-105.

27. Choi SC, Kim SJ, Choi JH, Park CY, Shim WJ, Lim DS. Fibroblast growth factor-2 and -4 promote the proliferation of bone marrow mesenchymal stem cells by the activation of the PI3K-Akt and ERK1/2 signaling pathways. Stem Cells Dev 2008; 17: 725-736.

28. Oh SA, Lee HY, Lee JH, Kim TH, Jang JH, Kim HW, et al. Collagen three-dimensional hydrogel matrix carrying basic fibroblast growth factor for the cultivation of mesenchymal stem cells and osteogenic differentiation. Tissue Eng Part $A$ 2012; 18: 1087-1100. 